\title{
Increasing Public Awareness of Direct-to-Consumer Genetic Tests: Health Care Access, Internet Use, and Population Density Correlates
}

\author{
Lila J. Finney Rutten, ${ }^{1}$ Sarah E. Gollust, ${ }^{2}$ Sana Naveed, ${ }^{3}$ and Richard P. Moser ${ }^{3}$ \\ ${ }^{1}$ Clinical Monitoring Research Program, SAIC-Frederick, Inc., NCI, Frederick, MD 21702, USA \\ ${ }^{2}$ Division of Health Policy and Management, University of Minnesota, 420 Delaware Street SE, MMC 729, Minneapolis, \\ MN 55455, USA \\ ${ }^{3}$ Division of Cancer Control and Population Sciences, National Cancer Institute, 6130 Executive Boulvard, MSC 7326, \\ Bethesda, MD 20892, USA \\ Correspondence should be addressed to Lila J. Finney Rutten, finneyl@mail.nih.gov
}

Received 19 April 2012; Revised 19 June 2012; Accepted 19 June 2012

Academic Editor: Angela Bryan

Copyright () 2012 Lila J. Finney Rutten et al. This is an open access article distributed under the Creative Commons Attribution License, which permits unrestricted use, distribution, and reproduction in any medium, provided the original work is properly cited.

\begin{abstract}
Uncertainty around the value of and appropriate regulatory models for direct-to-consumer (DTC) genetic testing underscores the importance of tracking public awareness of these services. We analyzed nationally representative, cross-sectional data from the Health Information National Trends Survey in $2008(n=7,674)$ and $2011(n=3,959)$ to assess population-level changes in awareness of DTC genetic testing in the U.S. and to explore sociodemographic, health care, Internet use, and population density correlates. Overall, awareness increased significantly from 29\% in 2008 to $37 \%$ in 2011 . The observed increase in awareness from 2008 to 2011 remained significant $(\mathrm{OR}=1.39)$ even when adjusted for sociodemographic variables, health care access, Internet use, and population density. Independent of survey year, the odds of awareness of DTC genetic tests were significantly higher for those aged 50-64 $(\mathrm{OR}=1.64)$, and 65-74 $(\mathrm{OR}=1.60)$; college graduates $(\mathrm{OR}=2.02)$; those with a regular source of health care $(\mathrm{OR}=1.27)$; those with a prior cancer diagnosis $(\mathrm{OR}=1.24)$; those who use the Internet $(\mathrm{OR}=1.27)$; and those living in urban areas $(\mathrm{OR}=1.25)$. Surveillance of awareness—along with empirical data on use of and response to genetic risk information-can inform public health and policy efforts to maximize benefits and minimize risks of DTC genetic testing.
\end{abstract}

\section{Introduction}

Ongoing genetic discoveries and technological innovation during the past decade have appreciably expanded the availability of genetic tests related to health conditions. Concomitant with the advancement of genetic science has been the development of two trends, the marketing of genetic tests directly to consumers (i.e., through paid advertisements in print media, television, and the Internet) and the direct availability of genetic tests to consumers (i.e., through the Internet) [1]. Regarding the latter, consumers can purchase genetic tests, often without involving their health care provider, that indicate personal risk for conditions ranging from trivial characteristics (e.g., earwax type) to serious health conditions (e.g., breast cancer, Alzheimer's disease) [1-3].

Both the direct marketing of genetic tests and their direct-to-consumer (DTC) availability have been controversial [4], with an increasing volume of health scholarship devoted to the topic $[1,2,4-10]$. While proponents of DTC tests argue that individuals should have the right to access their genetic information in a private setting (without going through the traditional health care setting), critics argue that DTC genetic testing has significant risks, both to the individuals and to the health care system $[1,2,4,6-10]$.

Since 2010, several regulatory actions have been taken in the United States with regard to DTC genetic testing, including letters to companies by the Food and Drug 
Administration and reports produced by the Government Accountability Office [3]. A fully informed policy analysis of the benefits and potential harms of DTC genetic testing is impossible without understanding the extent of consumer demand for, use of, and psychosocial and behavioral response to these services $[2,3,6,11-13]$. Awareness of DTC services is a necessary precursor to demand, as consumers (with rare exceptions, as when services are purchased as a gift) must be aware of the existence of these services before pursuing them. A systematic population-level assessment of awareness of DTC services reveals the extent of public interest in these services and the reach of marketing, which can help policymakers predict whether the risks and benefits of DTC genetic testing will be confined to a narrow subpopulation of consumers or is a more widespread population concern. Prior research examining awareness of DTC genetic testing has documented variability in overall levels of awareness and by geographic location, age, income, and education $[11,14,15]$. Limitations of prior research stem from the lack of national samples $[11,14]$ and failure to more fully explore demographic, behavioral, and geographic covariates of awareness to facilitate a more complete understanding of the implications of DTC marketing activities.

The Health Information National Trends Survey sought to fill this research gap by including a question about awareness of DTC genetic test marketing on a nationally representative survey platform [16]. Prior analysis of the 2008 Health Information National Trends Survey (HINTS) data explored associations of awareness with numeracy and identified racial and ethnic differences [16]. Our research provides a more detailed analysis of the 2008 data and includes analysis of 2011 HINTS data to explore trends in awareness over time.

Specifically, our research assesses changes in awareness of DTC genetic testing in the US population and explores factors associated with awareness including sociodemographic characteristics, cancer history, health care access, Internet use, and geographic differences. We focus on these factors for a variety of reasons. First, many of the currently available DTC genetic testing companies offer cancer risk testing as a major component of their service; in fact, the first major DTC multimedia advertising campaign for a genetic test was for breast cancer [17]. We included prior cancer diagnosis and family history of cancer in our analyses to explore whether individuals with particular interest in cancer are more aware of these services and thus may be part of the potential market for these services. Second, while proponents of DTC genetic testing have suggested that this mode of testing might facilitate greater access to genetic services in underserved areas [18], this has not yet been empirically examined. If awareness of these services is confined to urban areas and individuals who already have more health care access, then DTC genetic testing could exacerbate already-existing disparities in health care resources. Third, the majority of DTC genetic testing marketing efforts occur on-line. Thus, we were interested in exploring whether use of the Internet was associated with awareness of DTC genetic testing. Finally, given the unequal distribution of high speed Internet access in the USA with particular disparities in rural America, and the urban-focused efforts of traditional media marketing campaigns, we sought to discern whether there were differences in awareness of DTC genetic testing by population density [19].

\section{Materials and Methods}

2.1. Data Source. We analyzed data from two iterations of the Health Information National Trends Survey (HINTS 2008 and HINTS 2011). HINTS is a nationally representative survey of the US adult population that tracks trends in cancerrelated attitudes, knowledge, and behavior [20]. HINTS 2008 data were collected using a mixed mode, dual-frame design $(n=7,674)$ including both a list-assisted Random Digit Dial (RDD) Computer-Assisted Interview $(n=4,092)$ and comprehensive national listing of addresses available from the United States Postal Service for a mailed questionnaire $(n=$ $3,582)$. HINTS 2011 data were collected via a comprehensive national listing of addresses available from the United States Postal Service for a mailed questionnaire $(n=3959)$. Further details on survey design and sampling strategies for both surveys have been published elsewhere [21,22].

2.2. Data Collection and Response Rates. For HINTS 2008, the RDD data collection effort was conducted from January 7 to April 27, 2008, and the mail survey was conducted from January 15 to April 27, 2008. For the RDD arm, one adult from each sampled household was selected for an interview. The mail arm of HINTS 2008 included a stratified sample selected from a list of addresses, with an oversampling of minorities. The mail sample was a stratified cluster sample, in which the household was the cluster, therefore, for each sampled address all adults in the household were asked to complete a questionnaire. The response rate for the RDD household screener was $42.4 \%$, and the response rate for extended interview was $57.2 \%$, resulting in an overall RDD response rate of $24.2 \%$. The household response rate for the mail survey was $40 \%$, and the within-household rate was $77 \%$, resulting in an overall response rate of $31 \%$.

Data collection for HINTS 2011 was initiated in October 2011 and concluded in February of 2012. The sample design involved two stages wherein a stratified sample of addresses was selected from a file of residential addresses, and respondents were selected within each sampled household. Two methods of respondent selection were used: the "next birthday" method requested that the adult in the household with the next birthday complete the questionnaire and the "all adult" method requested that each adult in the household complete a questionnaire [22]. Household response rates were calculated separately for each respondent selection method [23]. For the next birthday method of respondent selection, the household response rate was $37.9 \%$ and the household response rate for the all adult method was 35.3\%. For the all adult method the household response rate was $84.6 \%$. The final response rate for HINTS 2011, determined by combining response rates across respondent selection method in proportion to the allocated sample, was $36.7 \%$. 


\subsection{Measures}

Awareness of Direct-to-Consumer Genetic Tests. The following question assessed awareness of DTC genetic tests in both 2008 and 2011: Genetic tests that analyze your DNA, diet, and lifestyle for potential health risks are currently being marketed by companies directly to consumers. Have you heard or read about these genetic tests?

Sociodemographic Variables. Sociodemographic variables included gender, age (18-34, 35-49, 50-64, 65-74, and 75+ years), education (less than high school, high school graduate, some college, and college graduate), annual household income (less than $\$ 35 \mathrm{~K}, \$ 35 \mathrm{~K}$ to less than $\$ 75 \mathrm{~K}$, and $\$ 75 \mathrm{~K}$ or more), and race/ethnicity (Hispanic, nonHispanic white, non-Hispanic black, and "other").

Health Care Access. Two indicators of health care access were included in our analyses: health insurance status and usual source of health care. Health insurance status was assessed with the following item in 2008: Do you have any kind of health care coverage, including health insurance, prepaid plans such as HMOs, or government plans such as Medicare? (yes/no). In 2011, this item was revised as follows: Do you have any of the following health insurance or health coverage plans: Insurance through a current or former employer or union (of you or another family member); Insurance purchased directly from an insurance company (by you or another family member); Medicare; Medicaid, Medical Assistance, or any kind of government assistance plan for those with low incomes or disability; TRICARE or other military health care; VA (including those who have ever used or enrolled for VA health care); or Indian Health Service. Responses to the 2011 item were recoded as yes/no to be comparable with 2008 wherein those who indicated having at least one source of health insurance were coded as yes.

In 2008 and 2011, regular source of health care was assessed with the following item: not including psychiatrists and other mental health professionals, is there a particular doctor, nurse, or other health professional that you see most often? Responses to both items were coded as yes/no.

Cancer History. Respondents were asked about their personal history of cancer in both 2008 and 2011 with the following question: Have you ever been diagnosed as having cancer? Respondents to both surveys were also asked: Have any of your family members ever had cancer? Responses were coded as yes/no.

Internet Use. The following item assessed use of the Internet: Do you ever go online to access the Internet or World Wide Web, or to send and receive e-mail? Responses were coded as yes/no.

Population Density. For HINTS 2008 and 2011, countylevel rural-urban continuum codes are determined from the US Department of Agriculture Economic Research Service for each respondent according to their geographic location. For our analyses, the original continuum represented by
9 rural-urban codes was recoded to create a two-level variable wherein counties in metro areas were coded as urban and those in non-metro areas were coded as rural.

2.4. Data Analysis. We used SUDAAN version 9.0.1 to estimate standard errors of point estimates for the complex survey data [24]. All data were weighted according to population estimates in the American Community Survey to provide representative estimates of the adult US population. Jackknife replicate weights were computed to get accurate variance estimates. To address the issue of nonindependence of responses from members of the same household, all respondents from the same household were assigned to the same replicate weights which accounts for clustering within the primary household sampling unit [25]. A crosstabulation with chi square of survey mode of administration for the 2008 data $(\mathrm{RDD} / \mathrm{mail})$ with the primary outcome variable, awareness of DTC genetic tests (yes/no), revealed that there were no mode of survey administration effects on the estimates for the RDD and mail survey; therefore, data from the RDD and mail survey were combined for our analyses.

Cross-tabulations and chi-square tests of association were conducted for awareness of DTC genetic tests by sociodemographic, health care access, Internet use, and geographic characteristics for each survey year. We created a combined dataset integrating data and relevant variables including sampling variables and weights from 2008 and 2011 resulting in a combined sample size of $n=11,633$. We then conducted a multivariable logistic regression analysis to examine independent associations with awareness including survey year, sociodemographic, health care access, Internet use, and population density using a forced entry method of variable selection. Missing data were treated listwise in the multivariable model and indicator variables were created for missing values for income ( $n=1760$ missing) and family history of cancer ( $n=1094$ missing) to reduce the impact of missing values for these variables on the model.

\section{Results}

In 2008, 29.3\% of the population was aware of DTC genetic tests. The percentage of the population aware of DTC genetic tests increased significantly to $36.9 \%$ in 2011 (Table 1). Cross-tabulation of the respondents' sociodemographic characteristics with awareness of DTC genetic tests in each survey year revealed several significant bivariable correlations (Table 1).

To assess whether the observed increase in awareness held while controlling for sociodemographic characteristics, health status, Internet use, and population density we conducted a multivariable analysis on the combined 2008 and 2011 data (Table 2). Survey year remained significantly associated with awareness with the additional variables included in the model; awareness in 2011 was significantly higher $(\mathrm{OR}=1.39)$ than in 2008. The odds of awareness of DTC genetic tests were significantly higher among those aged 50-64 $(\mathrm{OR}=1.64)$, and $65-74(\mathrm{OR}=1.60)$ compared to those aged 18-34. Awareness was also higher among college 
TABLE 1: Awareness of direct-to-consumer genetic testing by respondent characteristics.

\begin{tabular}{|c|c|c|}
\hline \multirow{3}{*}{ Respondent characteristic } & \multicolumn{2}{|c|}{ Weighted $^{1}$ population $\%$ aware of DTC genetic tests } \\
\hline & HINTS 2008 & HINTS 2011 \\
\hline & $n=7,674$ & $n=3,959$ \\
\hline Total $\left(\chi^{2}=32.64 ; P<0.0001\right)$ & 29.3 & 36.9 \\
\hline Gender & $\left(\chi^{2}=1.9 ; P=.18\right)$ & $\left(\chi^{2}=2.1 ; P=.15\right)$ \\
\hline Male & 30.2 & 35.0 \\
\hline Female & 28.3 & 39.1 \\
\hline Age & $\left(\chi^{2}=13.3 ; P<.0001\right)$ & $\left(\chi^{2}=11.0 ; P<.0001\right)$ \\
\hline $18-34$ & 23.3 & 30.3 \\
\hline $35-49$ & 31.1 & 36.3 \\
\hline $50-64$ & 34.9 & 45.9 \\
\hline $65-74$ & 32.4 & 42.2 \\
\hline $75+$ & 24.1 & 30.3 \\
\hline Annual income & $\left(\chi^{2}=32.7 ; P<.0001\right)$ & $\left(\chi^{2}=17.6 ; P<.0001\right)$ \\
\hline$<\$ 35 \mathrm{~K}$ & 25.7 & 29.0 \\
\hline$\$ 35 \mathrm{~K}$ to $<\$ 75 \mathrm{~K}$ & 25.4 & 35.6 \\
\hline$\$ 75 \mathrm{~K}$ or more & 37.9 & 46.7 \\
\hline Race/ethnicity & $\left(\chi^{2}=6.4 ; P<.01\right)$ & $\left(\chi^{2}=9.8 ; P<.0001\right)$ \\
\hline Non-Hispanic white & 30.9 & 41.5 \\
\hline Non-Hispanic black & 23.7 & 30.0 \\
\hline Hispanic/Latino & 24.9 & 24.2 \\
\hline Non-Hispanic other & 33.9 & 31.8 \\
\hline Education & $\left(\chi^{2}=48.5 ; P<.0001\right)$ & $\left(\chi^{2}=21.5 ; P<.0001\right)$ \\
\hline Less than high school & 22.9 & 21.0 \\
\hline High school & 21.5 & 30.0 \\
\hline Some college & 28.1 & 36.0 \\
\hline College graduate & 42.9 & 48.2 \\
\hline Health insurance & $\left(\chi^{2}=9.7 ; P<.01\right)$ & $\left(\chi^{2}=8.9 ; P<.005\right)$ \\
\hline Yes & 30.5 & 40.6 \\
\hline No & 24.2 & 32.8 \\
\hline Regular provider & $\left(\chi^{2}=14.3 ; P<.001\right)$ & $\left(\chi^{2}=24.3 ; P<.0001\right)$ \\
\hline Yes & 31.2 & 41.8 \\
\hline No & 25.6 & 28.6 \\
\hline Prior cancer diagnosis & $\left(\chi^{2}=8.5 ; P<.01\right)$ & $\left(\chi^{2}=23.6 ; P<.0001\right)$ \\
\hline Yes & 34.0 & 47.4 \\
\hline No & 29.0 & 35.9 \\
\hline Family history of cancer & $\left(\chi^{2}=5.0 ; P<.05\right)$ & $\left(\chi^{2}=5.2 ; P<.05\right)$ \\
\hline Yes & 31.0 & 40.5 \\
\hline No & 26.4 & 34.6 \\
\hline Internet use & $\left(\chi^{2}=23.0 ; P<.0001\right)$ & $\left(\chi^{2}=21.3 ; P<.0001\right)$ \\
\hline Yes & 31.7 & 40.2 \\
\hline No & 24.1 & 25.1 \\
\hline Rural-urban designation & $\left(\chi^{2}=6.2 ; P<.05\right)$ & $\left(\chi^{2}=2.3 ; P=.13\right)$ \\
\hline Urban & 30.2 & 37.6 \\
\hline Rural & 25.0 & 33.5 \\
\hline
\end{tabular}

${ }^{1}$ All data were weighted to be representative to the US population according to estimates from the American Community Survey.

graduates $(\mathrm{OR}=2.02)$ compared to those with less education. Those with a regular source of health care $(\mathrm{OR}=1.27)$ evidenced greater odds of awareness than those without. The odds of awareness of DTC genetic tests were significantly higher among persons with a prior cancer diagnosis
$(\mathrm{OR}=1.24)$ compared with those without. Those who used the Internet $(\mathrm{OR}=1.27)$ had greater odds of awareness compared to those who did not use the Internet and those living in urban areas $(\mathrm{OR}=1.25)$ had greater odds of awareness compared with those in rural areas. 
TABLE 2: Independent correlates of awareness of direct-to-consumer (DTC) genetic testing $(n=10,394)^{1}$.

\begin{tabular}{|c|c|c|c|}
\hline & $\begin{array}{l}\text { Odds } \\
\text { ratio }\end{array}$ & $\begin{array}{c}95 \% \text { confidence } \\
\text { interval }\end{array}$ & $P$ value \\
\hline \multicolumn{4}{|l|}{ Survey year } \\
\hline HINTS 2008 & 1.00 & - & - \\
\hline HINTS 2012 & 1.39 & $1.19-1.64$ & 0.0001 \\
\hline \multicolumn{4}{|l|}{ Gender } \\
\hline Female & 1.00 & - & - \\
\hline Male & 0.98 & $0.83-1.16$ & 0.8507 \\
\hline \multicolumn{4}{|l|}{ Age } \\
\hline $18-34$ & 1.00 & - & - \\
\hline $35-49$ & 1.26 & $0.99-1.60$ & 0.0583 \\
\hline $50-64$ & 1.64 & $1.31-2.05$ & 0.0000 \\
\hline $65-74$ & 1.60 & $1.18-2.18$ & 0.0031 \\
\hline $75+$ & 1.14 & $0.81-1.60$ & 0.4573 \\
\hline \multicolumn{4}{|l|}{ Race/ethnicity } \\
\hline NH white & 1.00 & - & - \\
\hline NH black & 0.79 & $0.62-1.00$ & 0.0499 \\
\hline Hispanic/Latino & 0.82 & $0.62-1.09$ & 0.1719 \\
\hline $\mathrm{NH}$ other & 0.87 & $0.65-1.17$ & 0.3628 \\
\hline \multicolumn{4}{|l|}{ Annual income } \\
\hline Less than $\$ 35,000$ & 1.00 & - & - \\
\hline$\$ 35,000$ to $<\$ 75,000$ & 0.90 & $0.73-1.13$ & 0.3689 \\
\hline$\$ 75,000$ or more & 1.22 & $0.97-1.53$ & 0.0896 \\
\hline Missing & 1.39 & $1.02-1.91$ & 0.0402 \\
\hline \multicolumn{4}{|l|}{ Education } \\
\hline Less than HS & 1.00 & - & - \\
\hline HS graduate & 1.05 & $0.75-1.46$ & 0.7765 \\
\hline Some college & 1.31 & $1.00-1.72$ & 0.0511 \\
\hline College graduate & 2.02 & $1.49-2.75$ & 0.0000 \\
\hline \multicolumn{4}{|l|}{ Health insurance } \\
\hline Yes & 1.00 & - & - \\
\hline No & 1.10 & $0.90-1.35$ & 0.3516 \\
\hline \multicolumn{4}{|l|}{ Regular provider } \\
\hline No & 1.00 & - & - \\
\hline Yes & 1.27 & $1.04-1.54$ & 0.0178 \\
\hline \multicolumn{4}{|l|}{ Prior cancer diagnosis } \\
\hline No & 1.00 & - & - \\
\hline Yes & 1.24 & $1.07-1.44$ & 0.0047 \\
\hline \multicolumn{4}{|l|}{ Family history of cancer } \\
\hline No & 1.00 & - & - \\
\hline Yes & 1.13 & $0.98-1.32$ & 0.0951 \\
\hline Missing $^{2}$ & 0.77 & $0.53-1.12$ & 0.1638 \\
\hline \multicolumn{4}{|l|}{ Internet use } \\
\hline No & 1.00 & - & - \\
\hline Yes & 1.27 & $0.97-1.67$ & 0.0823 \\
\hline \multicolumn{4}{|l|}{ Population density } \\
\hline Rural & 1.00 & - & - \\
\hline
\end{tabular}

TABle 2: Continued.

\begin{tabular}{|c|c|c|c|}
\hline & $\begin{array}{l}\text { Odds } \\
\text { ratio }\end{array}$ & $\begin{array}{l}\text { 95\% confidence } \\
\text { interval }\end{array}$ & $P$ value \\
\hline Urban & 1.25 & $1.05-1.49$ & 0.0144 \\
\hline \multicolumn{4}{|c|}{$\begin{array}{l}\text { Missing values in model are listwise; if any case is missing a value on any of } \\
\text { the variables they are dropped from the analyses. } \\
\text { 'This category includes (1) "Has no family" ( }(n=15),(2) \text { "Refused," (3) "Do } \\
\text { not know," and (4) missing for } 2008 \text { data; For the 2012 data, this category } \\
\text { includes (1) "Missing data (Not Ascertained)," (2) "Multiple responses } \\
\text { selected in error," and (3) "Not sure." }\end{array}$} \\
\hline
\end{tabular}

\section{Discussion}

Our nationally representative results suggest that while general levels of awareness of DTC genetic tests have increased in the past 4 years, increased awareness is not equally distributed throughout the population. Independent of survey year, the odds of awareness of DTC genetic tests were significantly higher for the following: those aged 50 74 , those with greater education, those with a regular source of care, those with a prior cancer diagnosis, those who use the Internet, and those living in urban areas. Estimates of awareness from 2008 are generally consistent with prior research $[11,14,15]$, and the differences in awareness of DTC genetic testing observed by age and education were similar to those reported in previous research $[11,16]$. Although we document a persistence of these differences across two time periods, thus advancing earlier work, our results also expand on previous research by documenting greater awareness of DTC genetic tests for those individuals with a regular source of care and those with a prior cancer diagnosis. Finally, use of the Internet and residence in population-dense regions of the country were associated with greater awareness of DTC genetic tests paralleling options for high speed Internet connections throughout the county [19].

Accurate understanding of the population prevalence of public interest in DTC testing is important to inform ongoing discussions of its public health and policy implications. Our results reveal that certain groups of the public have been reached by DTC marketing efforts to a greater extent than others; namely, higher SES populations with more Internet savvy. Thus, to the extent that DTC genetic testing has value for public health (a contention that remains under evaluation $[6,26]$ ), the consumers likely to reap the benefits are those already advantaged in health care. Our study also reveals the possibility that individuals with cancer risk may be particularly attracted to DTC modes of testing, supporting the importance of empirical research that focuses on the attitudes, beliefs, and responses to testing among subgroups defined by disease risk [27]. Of course, awareness of testing is likely to far exceed use of services; previous research has suggested that while $22 \%$ of people were aware of services in 2008, less than $1 \%$ had used them [15]. More research is needed to understand consumers' rationales for their decisions to actually pursue DTC genetic testing. Moreover, an in-depth analysis of the public health benefits and risks and policy implications of DTC genetic services will depend on the results of research, using both qualitative 
and quantitative research methods, on DTC service users. A wealth of recent initiatives to explore the impact of personal genomic risk information on individual users' attitudes, beliefs, mental health, health behaviors, and health services have already added, and will continue to add, to the evidence base $[3,12,13,26,28]$.

A few limitations are worth noting. The HINTS program provides data from rigorously developed samples based on cross-sectional surveys. As such, it is not possible to make inferences about causality in observed relationships. Another limitation of the HINTS data stems from the relatively low response rates. With the development of Caller ID and the progression toward cell phone only households, response rates for RDD surveys have fallen over the past decade $[29,30]$. However, recent methodological research suggests that the potential for bias resulting from declining $\mathrm{RDD}$ response rates may not be as significant for health surveys as previously assumed [30-32]. Considerable effort has also been made in the HINTS program to protect against biases introduced through modality, coverage, and sampling through use of dual frame administration in 2007-2008 [33]. The use of the mailed survey in 2008 and 2011 provides access to cell phone only households. Another limitation stems from missing data; in particular, in the multivariable model, missing data were treated listwise so cases with missing values on any of the variables included in the model were dropped from the model leading to a large number of missing values which may limit the generalizability of the results. However, to reduce the number of cases dropped from the model we created indicator variables to represent missing values for income and family history. Finally, it is important to note that our one-item measure of awareness of DTC genetic tests does not capture the complexity and multifaceted nature of the many types of tests available, and thus, is a relatively blunt measure of awareness. However, national survey tools are often constrained to measuring constructs of interest with only one or two items given the overall limits placed on survey length and respondent burden.

\section{Conclusions}

Controversy and uncertainty around the risks and benefits of DTC genetic testing, coupled with limited regulatory oversight $[1,34,35]$, underscore the importance of tracking public awareness of DTC genetic testing as a proxy for current and future demand for these services. The nationally representative data described herein reveals growing awareness of DTC genetic testing that is unequally distributed in the population. The HINTS program will continue to monitor awareness of DTC genetic testing to track changes over time.

\section{Acknowledgments}

This project has been funded in part with federal funds from the National Cancer Institute, National Institutes of Health, under Contract no. HHSN261200800001E. The content of this publication does not necessarily reflect the views or policies of the Department of Health and Human Services, nor does mentioning of trade names, commercial products, or organizations imply endorsement by the US Government.

\section{References}

[1] S. Hogarth, G. Javitt, and D. Melzer, "The current landscape for direct-to-consumer genetic testing: legal, ethical, and policy issues," Annual Review of Genomics and Human Genetics, vol. 9, pp. 161-182, 2008.

[2] T. Caulfield and A. L. McGuire, "Direct-to-consumer genetic testing: perceptions, problems, and policy responses," Annual Review of Medicine, vol. 63, pp. 23-33, 2012.

[3] C. S. Bloss, B. F. Darst, E. J. Topol et al., "Direct-to-consumer personalized genomic testing," Human Molecular Genetics, vol. 20, no. 2, pp. R132-R141, 2011.

[4] A. L. McGuire and W. Burke, "Health system implications of direct-to-consumer personal genome testing," Public Health Genomics, vol. 14, no. 1, pp. 53-58, 2011.

[5] ACOG Committee Opinion No. 409, "Direct-to-consumer marketing of genetic testing," Obstetrics \& Gynecology, vol. 111, no. 6, pp. 1493-1494, 2008.

[6] T. Caulfield, N. M. Ries, P. N. Ray, C. Shuman, and B. Wilson, "Direct-to-consumer genetic testing: good, bad or benign?" Clinical Genetics, vol. 77, no. 2, pp. 101-105, 2010.

[7] A. L. McGuire and W. Burke, "An unwelcome side effect of direct-to-consumer personal genome testing: raiding the medical commons," Journal of the American Medical Association, vol. 300, no. 22, pp. 2669-2671, 2008.

[8] A. L. McGuire, B. J. Evans, T. Caulfield, and W. Burke, "Regulating direct-to-consumer personal genome testing," Science, vol. 330, no. 6001, pp. 181-182, 2010.

[9] K. Offit, "Genomic profiles for disease risk: predictive or premature?" Journal of the American Medical Association, vol. 299, no. 11, pp. 1353-1355, 2008.

[10] A. J. Wolfberg, "Genes on the web-direct-to-consumer marketing of genetic testing," The New England Journal of Medicine, vol. 355, no. 6, pp. 543-545, 2006.

[11] K. A. Goddard, D. Duquette, A. Zlot et al., "Public awareness and use of direct-to-consumer genetic tests: results from 3 state population-based surveys, 2006," American Journal of Public Health, vol. 99, no. 3, pp. 442-445, 2009.

[12] C. S. Bloss, N. J. Schork, and E. J. Topol, "Effect of directto-consumer genomewide profiling to assess disease risk," The New England Journal of Medicine, vol. 364, no. 6, pp. 524-534, 2011.

[13] L. Goldsmith, L. Jackson, A. O'Connor, and H. Skirton, "Direct-to-consumer genomic testing: systematic review of the literature on user perspectives," European Journal of Human Genetics, vol. 20, no. 8, pp. 811-816, 2012.

[14] A. L. McGuire, C. M. Diaz, T. Wang, and S. G. Hilsenbeck, "Social networkers' attitudes toward direct-to-consumer personal genome testing," American Journal of Bioethics, vol. 9, no. 6-7, pp. 3-10, 2009.

[15] K. Kolor, T. Liu, J. S. Pierre, and M. J. Khoury, "Health care provider and consumer awareness, perceptions, and use of direct-to-consumer personal genomic tests, United States, 2008," Genetics in Medicine, vol. 11, no. 8, p. 595, 2009.

[16] A. T. Langford, K. Resnicow, J. S. Roberts, and B. J. ZikmundFisher, "Racial and ethnic differences in direct-to-consumer genetic tests awareness in HINTS 2007: sociodemographic and numeracy correlates," Journal of Genetic Counseling, vol. 21, no. 3, pp. 440-447, 2012. 
[17] M. F. Myers, M. H. Chang, C. Jorgensen et al., "Genetic testing for susceptibility to breast and ovarian cancer: evaluating the impact of a direct-to-consumer marketing campaign on physicians' knowledge and practices," Genetics in Medicine, vol. 8, no. 6, pp. 361-370, 2006.

[18] K. T. Hock, K. D. Christensen, B. M. Yashar, J. S. Roberts, S. E. Gollust, and W. R. Uhlmann, "Direct-to-consumer genetic testing: an assessment of genetic counselors' knowledge and beliefs," Genetics in Medicine, vol. 13, no. 4, pp. 325-332, 2011.

[19] National Telecommunications and Information Administration, "National Broadband Map," cited 2011 April, 09, 2012, http://broadbandmap.gov/.

[20] D. E. Nelson, G. Krepsa, B. Hesse et al., "The Health Information National Trends Survey (HINTS): development, design, and dissemination," Journal of Health Communication, vol. 9, no. 5, pp. 443-460, 2004.

[21] D. Cantor, K. Coa, S. Crystal-Mansour, T. Davis, S. Dipko, and R. Sigman, Health Information National Trends Survey (HINTS) 2007: Final Report, 2009.

[22] L. Finney Rutten, T. Davis, E. Burke Beckjord, K. Blake, R. P. Moser, and B. W. Hesse, "Picking up the pace: changes in method and frame for the health information National Trends Survey (2011-2014)," Journal of Health Communication, vol. 17, no. 8, 2011.

[23] T.A.A.F.P.O.R., "Standard Definitions: Final Dispositions of Case Codes and Outcome Rates for Surveys, 7th edition," AAPOR, 2011.

[24] Research Triangle Institute, "SUDAAN Version 9," Research Triangle Institute, Raleigh, NC, USA, 2008.

[25] K. M. Wolter, Introduction to Variance Estimation, Springer, New York, NY, USA, 1985.

[26] C. M. McBride, S. H. Alford, R. J. Reid, E. B. Larson, A. D. Baxevanis, and L. C. Brody, "Characteristics of users of online personalized genomic risk assessments: implications for physician-patient interactions," Genetics in Medicine, vol. 11, no. 8, pp. 582-587, 2009.

[27] S. W. Gray, R. C. Hornik, J. S. Schwartz, and K. Armstrong, "The impact of risk information exposure on women's beliefs about direct-to-consumer genetic testing for BRCA mutations," Clinical Genetics, vol. 81, no. 1, pp. 29-37, 2012.

[28] E. S. Gordon, G. Griffin, L. Wawak, H. Pang, S. E. Gollust, and B. A. Bernhardt, “'It's not like judgment day': public understanding of and reactions to personalized genomic risk information," Journal of Genetic Counseling, vol. 21, no. 3, pp. 423-432, 2012.

[29] S. J. Blumberg, J. V. Luke, and M. L. Cynamon, "Telephone coverage and health survey estimates: evaluating the need for concern about wireless substitution," American Journal of Public Health, vol. 96, no. 5, pp. 926-931, 2006.

[30] M. Fahimi, M. Link, A. Mokdad, D. A. Schwartz, and P. Levy, "Tracking chronic disease and risk behavior prevalence as survey participation declines: statistics from the behavioral risk factor surveillance system and other national surveys," Preventing Chronic Disease, vol. 5, no. 3, p. A80, 2008.

[31] E. M. Gentry, W. D. Kalsbeek, and G. C. Hogelin, "The behavioral risk factor surveys: II. Design, methods, and estimates from combined state data," American Journal of Preventive Medicine, vol. 1, no. 6, pp. 9-14, 1985.

[32] D. E. Nelson, E. Powell-Griner, M. Town, and M. G. Kovar, "A comparison of national estimates from the National Health Interview Survey and the Behavioral Risk Factor Surveillance System," American Journal of Public Health, vol. 93, no. 8, pp. 1335-1341, 2003.
[33] D. Cantor et al., "Health Information National Trends Survey (HINTS) 2007," Westat, Rockville, Md, USA, 2009.

[34] B. M. Kuehn, "Risks and benefits of direct-to-consumer genetic testing remain unclear," Journal of the American Medical Association, vol. 300, no. 13, pp. 1503-1505, 2008.

[35] J. Kaye, "The regulation of direct-to-consumer genetic tests," Human Molecular Genetics, vol. 17, no. 2, pp. R180-R183, 2008. 


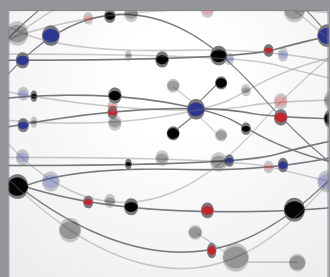

The Scientific World Journal
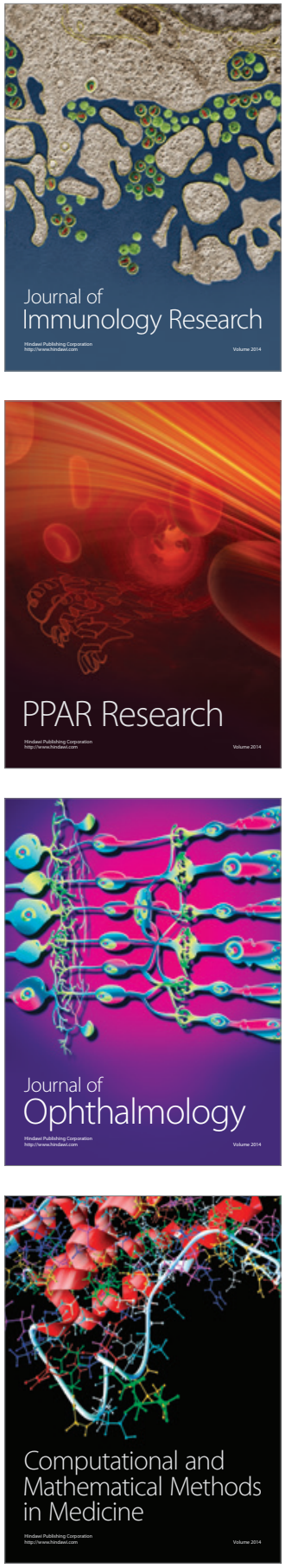

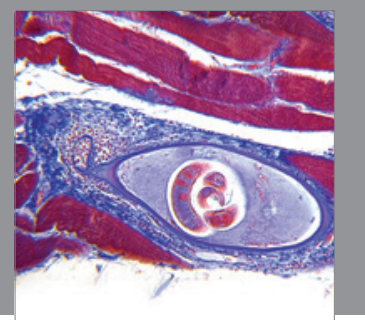

Gastroenterology

Research and Practice
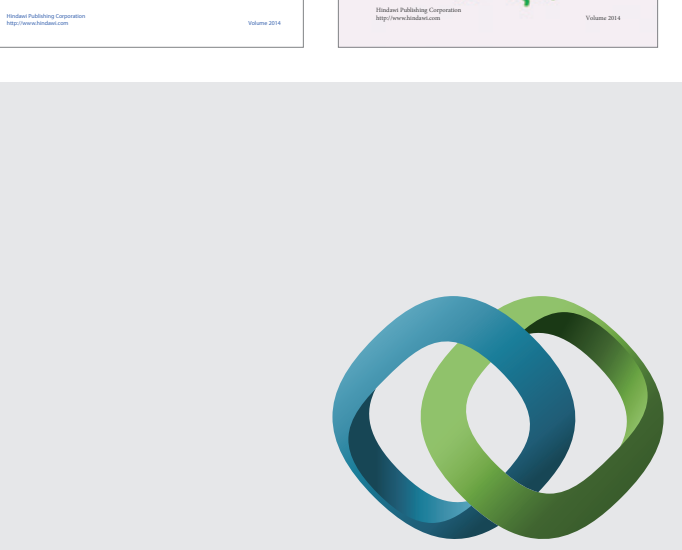

\section{Hindawi}

Submit your manuscripts at

http://www.hindawi.com
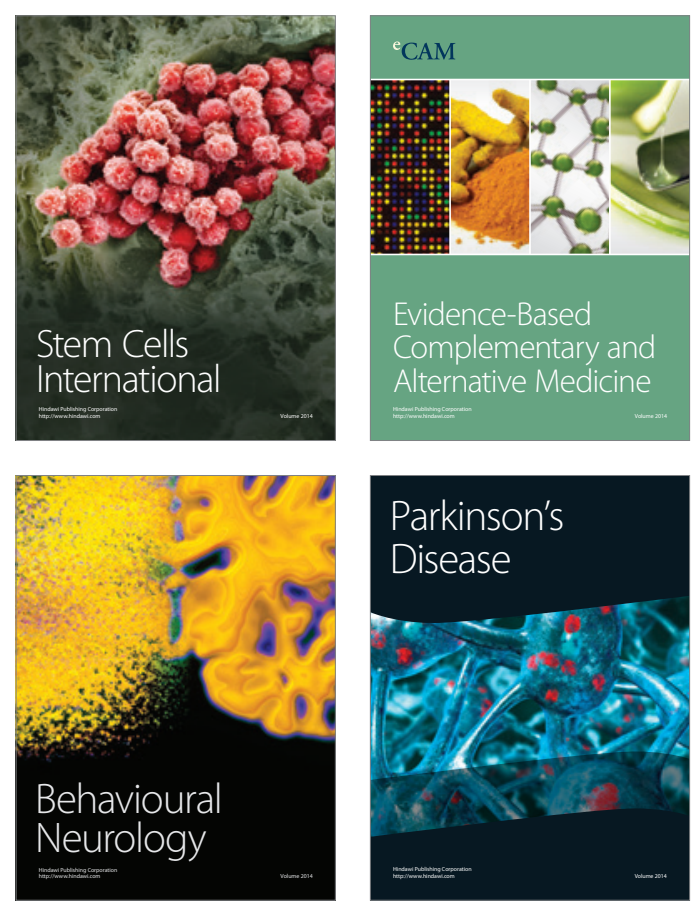

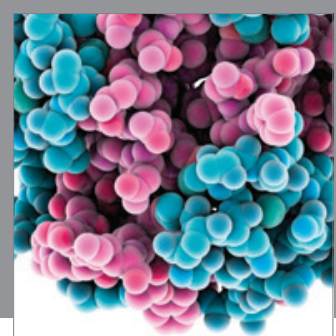

Journal of
Diabetes Research

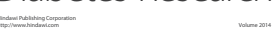

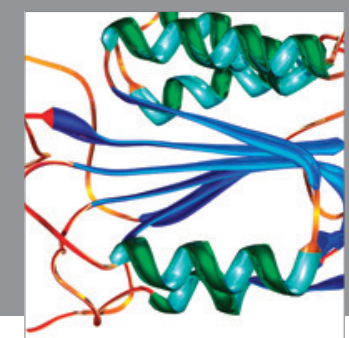

Disease Markers
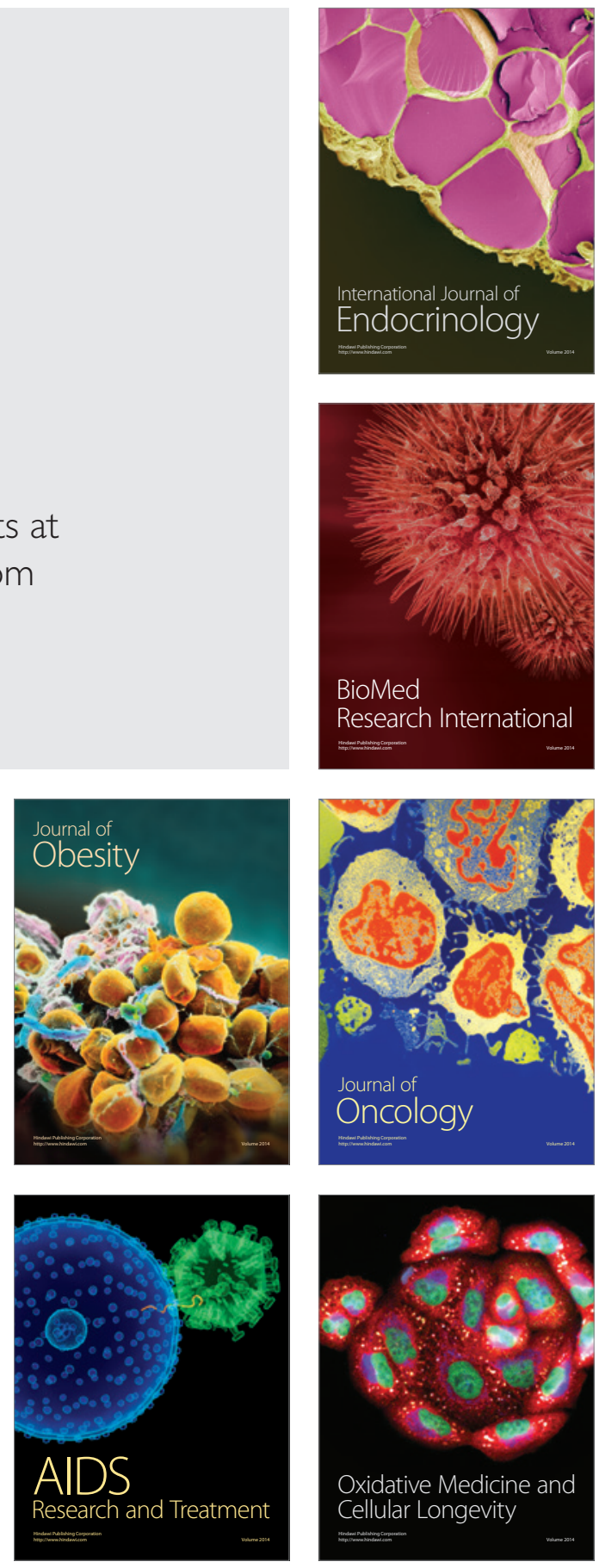